\title{
Innovation in Language Education: Enriching Arabic Language Learner Experiences and Proficiency in2D and 3D Environments
}

\author{
Abdel-Hakeem Kasem \\ Deakin University, Faculty of Arts and Education, Melbourne, AUSTRALIA
}

\begin{abstract}
Global language and cultural communicative competency is an ever increasing requirement in our connected world. Learners of Arabic at the only five Australian universities where Arabic is taught have access to predominantly on-campus delivery modes. One of the main challenges learners face when learning another language (L2) in an academic setting in countries where that language is not actively used - so little L2 exposure - is that it is harder to provide meaningful contexts for learning. This restriction in L2 exposure in the formal academic framework is due to the limited face-to-face learning time and, more significantly, is compounded by lack of exposure to the language's authentic use settings. Students are often isolated from the target language's authentic discourse communities and native speakers. This situation is exacerbated for Cloud (online) students, studying in relative isolation. All of these factors make developing communicative oral fluency in Modern Standard Arabic (MSA) moredifficult and challenging for many learners.
\end{abstract}

This paper will discuss two innovative approaches used at Deakin University in Melbourne, Australia to enable learners of Arabic at Deakin University to practice their developing skills by listening, practising, and experiencing directly how the language is used outside the classroom boundaries as well as allow learners to develop their oral and cultural communicative competency by engaging them in simulating and evolving authentic language scenarios with native Arabic speakers through the Virtual World (VW).

Key Words:-Arabic, Arabic Online, Blended Learning, Virtual Worlds

\section{INTRODUCTION}

Global language and cultural communicative competency is an ever increasing requirement in our connected world. Learners of Arabic at the only five Australian universities where Arabic is taught have access to predominantly on-campus delivery modes. Deakin Arabic is a well-established language program in Australia emphasising communicative competence, and innovative learning and teaching methodologies. Global language and cultural communicative competency is an ever-increasing demand in our globally connected world. To develop communicative competence in any language, language educators agree that for most learners one of the most significant motivation triggers in learning a new language is not an interest in the object itself, the language, but the yearning to communicate through the language.

One of the main challenges students face when learning another language (L2) in an academic setting in countries where that language is not actively used - so little L2 exposure - is that it is harder to provide meaningful contexts for learning. This restriction in L2 exposure in the formal academic framework is due to the limited face-to-face learning time and, more significantly, is compounded by lack of exposure to the language's authentic use settings. Students are often isolated from the target language's authentic discourse communities and native speakers. This situation is exacerbated for Cloud (online) students, studying in relative isolation. All of these factors make developing communicative oral fluency difficult and challenging for many learners.

This paper will discuss the two innovative approaches used to create engaging real-time learning settings that are flexible, accessible and that target today's mobile and global learners. The two approaches enable learners of Arabic at Deakin University to practice their developing skills by listening, practising, and experiencing directly how the language is used outside the classroom boundaries through the Deakin's learning management system Desire 2 Learn (D2L), as well as allow learners to develop their oral and cultural communicative competency by engaging them in simulating and evolving authentic language scenarios with native Arabic speakers through the Virtual World (VW).

The first approach was developed between 2006 - 2011. Since 2006, the author engaged in designingand developing an innovative world-class flexible online Arabic language and culture program in asynchronous mode, integrating appropriate use of technology with a scholarly approach, underpinned by systematic linguistic research of foreign language learning (Kasem, 2014). The online course material developed uses an outcomes-based approach to course design which takes the view that technology can be both tool and 
tutor in language education. The role of technology in language education is examined as an aspect of curriculum design, that is, the starting point is needs analysis and the resulting curriculum, rather than technology. Innovative and sophisticated course material were developed to provide interactivity by linking audio to the written Arabic text and by introducing a series of matching exercises and other authentic language activities to allow practice to aid the language learning process and make language materialmore readily available to learners outside the classroom anywhere and at any time.

An ongoing analysis and evaluation of the students' learning experiences in the Arabic Online Environment at Deakin University reveals that students enjoy studying Arabic and find the onlineteaching and learning environment a welcome and integral part of their study regime that supports the development of independent learners who can manage their own learning experience at a time and a place of their choice in a very relaxed and non-threatening environment (Kasem, 2014).

The results of this online development have been very positive for educators as well as students as evidenced by the outstanding recognitions gained by the author. In 2009, he received a Teaching Excellence Award for pioneering an Arabic program that led to innovative and creative approaches to teaching foreign languages at tertiary level nationally in Australia.

The second approach, which is still in the design and development stage, aims to develop a first of its kind Arabic virtual immersive 3-D learning worlds in Second Life (SL) to create authentic and real-time learning spaces that are flexible, accessible and target today's mobile learners. All the affordances of virtuality and 3-D virtual worlds will be utilised to engage students in simulating and evolving authentic language scenarios with native Arabic speakers in Oman as well as other Arabic speaking countries, which would enrich student learning experiences. The VW design is expected to be completed and piloted in 2018/19.

\section{ARABIC IN AUSTRALIA}

Arabic is considered a priority language in many Australian government reports and is seen as a language of strategic importance to Australia's national interest. Relatively recent global events have highlighted the geo-political importance of the Arabic-speaking world combined with greater awareness of the business opportunities available in this region of the world, the need for Australians to develop a greater appreciation of the Middle East culture together with the need to foster social relationships and friendships between Australians and the Arab world. All these factors have pushed demand for learning Arabic beyond government and academic environments and into the wider community.

Arabic is currently taught in 5 of Australia's leading tertiary institutions. - Deakin University and the University of Melbourne in the Victoria, the University of New South Wales and the University of Western Sydney in New South Wales, and the Australian National University in Australia's capital territory, Canberra. The Arabic programs offered at four of these institutions are delivered under traditional on-campus delivery format. While appropriate for some audiences, traditional on-campus delivery formats are not convenient for business owners, professionals, consultants, government workers, diplomats, teachers, and other full-time employees requiring Arabic language training or for people in rural and remote Australia who wish to study the language.

\section{DEAKIN ARABIC LANGUAGE AND CULTURE PROGRAM}

Deakin Arabic is a well-established language program in Australia since 1989 with an emphasis on communicative competence and innovative teaching methodologies. Its distinguishedcharacteristics lie in the areas of innovative online approaches supporting student experiential learning and the use of in-country internship programs.

Deakin University is the only university in Australia which has developed, since 2006, an innovative and unique program for teaching both Arabic language and culture whichutilises cutting-edge technology and course-tool applications in an asynchronous mode. This program is integral to the student experience.

\section{THE CHALLENGES LEARNERS OF ARABIC FACE}

One of the main challenges students face when learning another language (L2) in an academic setting in countries where that language is not actively used - so little L2 exposure - is that it is harder to provide meaningful contexts for learning. This restriction in L2 exposure in the formal academic framework is due to the limited face-to-face learning time and, more significantly, is compounded by lack of exposure to the language's authentic use settings. Students are often isolated from the target language's authentic discourse communities and native speakers. This situation is exacerbated for Cloud (online) students, studying in relative isolation. In order to address these issues we have developed an innovative and creative Arabic online teaching and learning environment (running in Desire 2 Learn (D2L) ) to enrich students' learning experiences and enable students outside the classroom to listen, practise, and experience directly how the language is used. 
In order to address these challenges and increase learners' 'comprehensible input' (Krashen, 1983; Peregoy\& Boyle, 2001) the author, since 2006, has developed an innovative world-class flexible online language and culture program in asynchronous mode. The complete development of the Arabic online environment enabled us to offer Arabic for the first time in flexible (blended learning) mode in 2010. The online teaching and learning material,that was developed over several years, is divided into three essential learning modulescovering the beginners and intermediate levels (See illustration below):The Learning Objectives modules provide the primary methods of learning the course material; the Practice models offer students complementary practice and allows them through carefully designed exercises and language activities to practice the lessons' learning objectives and improve their competency level; and the Assessment modules offer students the opportunity to self-assess and test their knowledge. The online learning environment is totally interactive, providing participating students with immediate feedback on their work. It also provides opportunities for interaction through the synchronous communication tool Blackboard Collaborate (BbC), email, discussion boards and chat rooms, enabling learners to communicate regularly and frequently with their tutors and classmates for an enhanced learning experience.

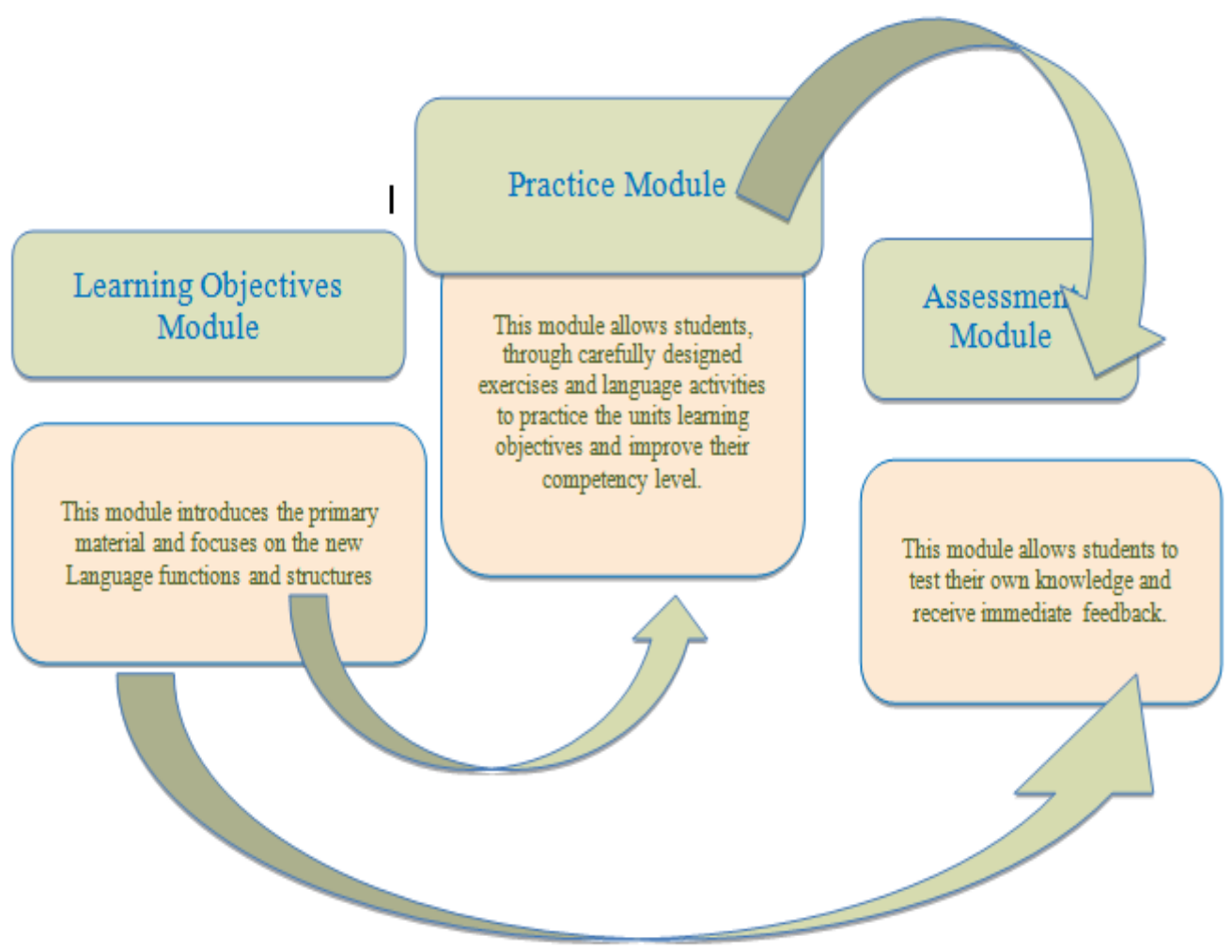

V. BLENDED LEARNING

The Bended Learning (BL) approach used in the course combines both face-to-face teaching and online learning with the tutor/instructor acting as a facilitator (Oliver and Trigwell, 2005; Bonk, 2006; Sharma, 2010; Sharma \& Barrett, 2007). This model (BL) was gradually introduced in 2008 to the first year students (beginners level) followed by second and third yearlevels in 2009 and 2010 (lower and upper intermediate). In this model on-campus students attend 3.5 hours of face to face classes per week. They are also expected to spend 6-8hours a week working independently on the online activities. While the face-to-face component of the course focuses mainly on the developing students" fluency through in-class discussion, the online environment activities focus more on developing students' critical thinking skills. Cloud (Online) students, on the other hand, are expected to watch the recorded lectures of the weekly lessons at home and attend a two-hour virtual class which was conducted through Blackboard Collaborate (BbC). BbC sessions focus on developing learners' oral fluency skills through discussions and other virtual class activities.

\section{EVALUATION OF THE BLAPPROACH}

In 2011 and after the introduction of the BL approach to all students studying Arabic at Deakin (Level 1, 2 and 3).It was necessary to evaluate this new experience. A research project was carried out to evaluate the effectiveness of the online resources and the blended learning approach used (Kasem 2014, 2015). A questionnaire was given to 127 students (68 females and 59 males) in the Beginners and Intermediate levels at 
the end trimester 2, 2010. 114 students completed and returned the survey (response rate $=89.7 \%$ ). The questionnaire elicited information about 15 statements relating to:

- students' perception of the Arabic online environment

- their satisfaction with the BL model of teaching and learning

- their overall satisfaction with Deakin Arabic language program.

All students surveyed studiedArabic as part of the Arabic major study or as an elective (Kasem 2014). Students were asked to choose a response using a Likert-type scale of 1 to 5 , where 1= "Strongly disagree", or the lowest most negative impression, $3=$ "neutral", and $5=$ "strongly agree", or the highest, most positive impression.In reporting results, the percentages are of the "Strongly Agree" and "Agree" were combined together to form a single "Agree" category, also the Disagree and Strongly Disagree were combined together to form a single "Disagree" category.

The analysis of the data obtained from the survey revealed the following results:

- Overall satisfaction with the Arabic online environment was high. With $88 \%$ of the respondents thought the online environment was well designed and easy to navigate. $78.9 \%$ thought the visual design of the site added interest and appeal, and 83.7 stated that they were able to find the information needed on the site, and 86.5 stated that they understood the relationship between the 3 learning modules. However, only 71.4 said they did not experience difficulties in accessing the online environment.

- Overall, Students expressed great satisfaction in the BL approach and the balance between the activities students do in the face to face classes and the activities they do in the online environment. They see great value in the on-line resources as it offers them flexibility and convenience and they see it as an extension and reinforcement of what they learn in the F2F.

- The great majority of students (91.3\%) found the Arabic online environment a valuable and important part of their study.

- $78.8 \%$ stated that they found the online resources engaging and motivating;

- 80.4 thought the online activities and the face-to-face activities were balanced; and complement each other;

- $88 \%$ of students, however, found the face-to-face activities more engaging and motivating than the on-line environment.

The above study showed that the online learning environment can be an effective tool in Second language acquisition because it helps in creating learning environments rich with opportunities for students to develop communicative competence while providing authentic communication. Furthermore, a balanced BL approach can be an effective tool in SLA, because it can be an efficient and convenient way to provide accurate, understandable materials to SL learners. It provides flexible access to content and instructions anytime and from any place at an individual pace and improves student learning outcomes.

Other important finding form this study was that the online teaching and learning environment supports thedevelopment of independent learners who can manage their own learning experience at a time and a place of their own choice. This allows for self-paced learning styles, and increased risk-taking (D'Aquila, 99), which is important in SLA. Online learning also reduces learners' anxiety by providing a non-judgemental, independent learning environment since studentsdon't need to perform before their peers. As a result students aremore likely to use new words and more complex language structures. Online learning can be engaging and entertaining and has the potential to increase student motivation and learning outcomes.

\section{DEVELOPING ARABIC ORAL AND CULTURAL COMPETENCY IN THE VIRTUAL WORLD}

Although the BL approach we have introduced since the development of the Arabic online teaching and learning resources at Deakin University has been successful and effective in providing students with opportunities to practice the language in an interactive manner outside the classroom boundaries and improve their learning outcomes, students felt their oral fluency was still lacking. This was mainly due to the lack of opportunities to interact withnative of speakers of Arabic outside the classroom.

Providing students with opportunities to meet and interact with native speakers of Arabic is at the heart of the second approachwhich we are in the process of developing in collaboration with other Australian and international universities.To enrich Arabic learners competency and fluency we plan to launch a new project that would extend the2D online language learning environment available at Deakin University to a rich immersive 3D platform that unites Arabic learners across the globe to communicate in dialect and through standard Arabic, irrespective of locale where authentic language interaction becomes possible in 3D online platform - irrespective of war-ravaged Arab countries, or the decimation of historical sites and cities, or security travel risks and costs. With the ever increasing use of blended, cloud, and virtual learning approaches and the evolution and maturity of immersive 3-D virtual worlds, their potential for engaged, multiuser, experiential language learning is exciting (see Carr, Oliver \& Burn, 2010; Dass, Dabbagh\& Clarke, 2011; , Gregory et al., 
2010, 2014, 2015; Lan, Chen, Li \& Grant, 2015; Salmon, 2009; Savin-Baden, 2010; Panichi\&Deutschmann, 2012; Pasfield-Neofitou, Huang \& Grant, 2015; Sajjanhar, 2012, 2014; Savin-Baden et al., 2010; Thomas, 2008; Warburton, 2009). The new project will create a vibrant immersive educational 3D environment for Arabic to address the many limitations of face-to-face foreign language learning in which to practice language fluency with native speakers in real-time dynamic environments with native speakers.

Virtual worlds are being used in a multitude of ways for diverse teaching and learning activities ranging from scenarios, virtual exhibitions, galleries and excursions, role-play simulations, experimentation, and language development to name a few (Gregory et al. 2010, 2011). Virtual worlds are increasingly being used to create learning experiences that are complex, rich, immersive and authentic - and even impossible in real-world settings such as crossing geographical country boundaries for language learning. Virtual worlds can potentially offer 'another world' of being 'in-world'. The proposed 3D immersive Arabic language learning environment will not only provide a strongly immersive "simulated realism" (Sykes, Oskoz\& Thorne, 2008, p. 538) but an "emotional connection" to learning (ibid) to capitalise on the affordances of Web 2.0 and 3D VW learning technologies (Grant \&Clerehan, 2011; Grant \& Huang, 2010, 2012; Sykes, Oskoz\& Thorne, 2008). It is a level playing field, an egalitarian space, which is only supported by keyboarding skills and personality" (Hundsberger, 2009, online). Also, because, facial expression may be reduced in virtual environments, then language may be used "in a very precise way ... to compensate for the lack of body language" (Hundsberger, 2009 , online). Further, the immersive Arabic learning environment would have tremendous potential to provoke learner agency (Ahearn, 2001). Whilst there has been some exploration of foreign language learning and Web 2.0 technologies (Thomas, 2008), using immersive 3D virtual world technologies for Arabic language learning is almost non-existent (Wang \&Wasquez, 2012). This opens up a niche pedagogical opportunity to be explored, developed, harnessed, and researched. This project will be an extension to and will complement the already impressive 2D online presence that Deakin University, providing a much needed immersive 3D shareable learning and teaching platform.

Specifically, the development of the Arabic 3D VW environment will:

- Provide opportunities for oral language practice in immersive dynamic environments through specific and exploratory synchronous and asynchronous language activity scenarios across literature and literary figures, historical sites and cities, religious and cultural festivals, modern day airports and museums, for example;

- Connect native Arabic speakers with Australian learners of Arabic to encourage cross-cultural exchange and understanding;

- Provide a sustainable, shared, immersive platform to enrich Arabic learners' experiences globally towards a much needed resurrected Arabesque imaginary to enhance and enrich their Arabic language proficiency and cultural competency.

This immersive Arabic VW platform will bring Arabic 'to life' in an immersive, spatial, aesthetic and embodied way (Dalgarno et al., 2011) by virtue of the vibrant 3D environment. Key features of virtuality are that learners engage in shared world building through learning scenarios that afford learners both the ability to exercise their language skills and also to connect to cultural mores and knowledge. For example, engaging with Arabic knowledge around the golden age of Islamic science where students can engage with the personas and works of historically important scientists in various fields and pursue objectives that involve talking to others and negotiating the sharing of information, can be stimulating and brought to life beyond static texts, videos and images. In scenarios such as these, learners will not only enjoy the gamified elements of pursuing goals but also immerse themselves in the culture and history connected to the language they are studying. Other scenarios might involve different historical contexts such as contemporary political, aesthetic, professional, and ethical discussions. The rationale for using VWs is strong as it provided immersive environments that are impossible via online 2D platforms and video engagement. One of the main challenges students face when learning another language (L2) in an academic setting in countries where that language is not actively used - so little L2 exposure - is that it is harder to provide meaningful contexts for learning. This restriction in L2 exposure in the formal academic framework is due to the limited face-to-face learning time and, more significantly, is compounded by lack of exposure to the language's authentic use settings. Students are often isolated from the target language's authentic discourse communities and native speakers. Further, to develop communicative competence in any language, language educators agree that for most learners one of the most significant motivation triggers in learning a new language is not an interest in the object itself, the language, but the yearning to communicate through the language. In spite of this, the traditional language classroom is all too often 'make-believe'; foreign language learners are forced into constructed artificial communicative situations on more or less relevant topics, where they can easily revert to their first language. Consequently, one of the main motivational forces for language learning is not exploited, namely the need and wish to communicate. In bringing together Arabic language learners with other Arabic native speakers in Oman, UAE, and other Arabic- 
speaking countries for some of the language activities in the Arabic VW 3D environment, will no doubt increase the scope for cross-cultural interactions so that Arabic becomes a viable option for meaningful communication. Further, given the decimation and destruction of so many Arab countries and their historical cities and cultural icons, the virtual 3D environment to be developed resurrects decimated cultural icons and cities and traverses the impossibilities of physical locales to create an authentic immersive 3D language engagement exchange platform. This project envisions a rich VW technology platform for Arabic.

\section{CONCLUSION}

One of the main challenges students face when learning another language (L2) in an academic setting in countries where that language is not actively used - so little L2 exposure - is that it is harder to provide meaningful contexts for learning. This restriction in L2 exposure in the formal academic framework is due to the limited face-to-face learning time and, more significantly, is compounded by lack of exposure to the language's authentic use settings. Students are often isolated from the target language's authentic discourse communities and native speakers. All of these factors make developing communicative oral fluency difficult and challenging for many learners.

In order to address these challenges it was important to develop two approaches that use $2 \mathrm{D}$ and $3 \mathrm{D}$ environment integrating appropriate use of technology with a scholarly approach, underpinned by systematic linguistic research of foreign language learning. This paper has shown that use of $2 \mathrm{D}$ environment can create learning environments rich with opportunities for students to develop their language skills. It can also be effective in developing students' critical thinking skills and increase their 'comprehensible input'.

One of the main motivational forces for language learning is the need and wish to communicate through the language.

While the use of the 2D environment has been successful and effective in providing students with opportunities to practice the language in an interactive manner outside the classroom boundaries and improve their learning outcomes, students felt their oral fluency was lacking due to the lack of opportunities to interact with native of speakers of Arabic outside the classroom. It is hoped that with the development and creation, over the next two years, ofa real-time dynamic and vibrant immersive educational 3D immersive environment,and by bringing together Arabic language learners in Australia to engage with native speakers in Oman and many other Arabic-speaking countries, this will increase and enhance the oral proficiency and cultural understanding of Australian university learners of Arabic.

\section{REFERENCES}

[1] Ahearn, L. M. (2001). Language and agency. Annual Review of Anthropology, 30, 109-137.

[2] Bonl., C. J., Kim, K-J. and Zeng, T. (2006). Future directions of blended learning in higher education and work-place settings. In Bonl., C. J. and Graham, C.R. (eds), The handbook of blended learning: Global perspectives, local designs (pp.550-567). San Francisco, CA: Pfeiffer Publishing Inc.

[3] Carr, D. Oliver, M., Burn, A. (2010). Learning, teaching and ambiguity in virtual worlds. In Researching Learning in Virtual Worlds. Peachey, A, Gillen, J, Livingstone, D, Smith-Robbins, S. (eds) UK : Springer.

[4] Dalgarno, B., \& Lee, M. J. W. (2010). What are the learning affordances of 3-D virtual environments? British Journal of Educational Technology, 41(1), 10-32. doi:10.1111/j.1467-8535.2009.01038.x

[5] Dalgarno, B., Lee, M. J. W., Carlson, L., Gregory, S. \& Tynan, B. (2011). An Australian and New Zealand scoping study on the use of 3D immersive virtual worlds in higher education. Australasian Journal of Educational Technology, 27(1), 1-15. Retrieved from http://dx.doi.org/10.1037/00332909.112.1.155

[6] Dalgarno, B., Lee, M. J. W., Carlson, L., Gregory, S. \& Tynan, B. (2011). An Australian and New Zealand scoping study on the use of 3D immersive virtual worlds in higher education. Australasian Journal of Educational Technology,27(1), 1-15. http://dx.doi.org/10.1037/0033-2909.112.1.155

[7] Dass, S., Dabbagh, N., \& Clark, K. (2011). Using virtual worlds. Quarterly Review of Distance Education, 12(2), 95-111.

[8] D"Aquila. L.C. (1999). Computer-assisted learning toward the national and New York standards for German. Dissertation Abstracts International, 60 (07), 2413A. (UMI No. 9936779)

[9] Grant, S., \&Clerehan, R. (2011). Finding the discipline: Assessing student activity in Second Life. Australasian Journal of Educational Technology, 27(5), 813-828. http://www.ascilite.org.au/ajet/ajet27/grant.html 
[10] Grant, S., \& Huang, H. (2010). The integration of an online 3D virtual learning environment into formal classroom-based undergraduate Chinese language and culture curriculum. Journal of Technology and Chinese Language Teaching, 1(1), 2-13. http://www.tclt.us/journal/2010v1n1/granthuang.pdf

[11] Grant, S., \& Huang, H. (2012). Learning a Second Language in Second Life. In T. Islam, O. Lee, J. Peterson \& M. Piscioneri (Eds.), Effectively Implementing Information Communication Technology in Higher Education in the Asia-Pacific Region. Hauppauge, NY: Nova Science Publishers.

[12] Gregory, S, et al. (2014), Rhetoric and reality: critical perspectives on education in a 3D virtual world', Ascilite 2014, New Zealand, 00, pp. 279-289.

[13] Gregory, S., \& Masters, Y. (2012). Real thinking with virtual hats: A role-playing activity for pre-service teachers in Second Life. In M. J. W. Lee, B. Dalgarno\& H. Farley (Eds), Virtual worlds in tertiary education: An Australasian perspective. Australasian Journal of Educational Technology, 28(Special issue, 3), 420-440.

[14] Gregory, S., Jacka, L., Hillier, M., \& Grant, S. (2015). Using virtual worlds in rural and regional educational institutions. Australian \& International Journal of Rural Education, 25(2), 73-90.

[15] Gregory, S., et al. (2010). Australian higher education institutions transforming the future of teaching and learning through 3D virtual worlds. In C. H. Steel, M. J. Keppell, P. Gerbic, \& S. Housego (Eds), Curriculum, technology \& transformation for an unknown future. Proceedings of the 27th ASCILITE Conference (pp. 399-415). Brisbane, Australia: The University of Queensland. http://www.ascilite.org.au/conferences/sydney10/Ascilite\%20conference\%20proceedings\%202010/Greg ory-full.pdf

[16] Hundsberger, S. (2009). Arcadia@ cambridge: rethinking the role of the research library in a digital age. http://arcadiaproject.lib.cam.ac.uk/docs/second life.pdf

[17] Kasem, A. (2015). The Teaching of Arabic Online at Deakin University: Experiences and Challenges. In Al-Baghdadi, Z (ed), A. Teaching Arabic Online: Expectations and Reality, pp 175-218, King Saud University Publication, Riyadh.

[18] Kasem, A. (2014). The Effect of Blended Learning in the Teaching of Arabic to Non-native Speakers: Deakin University as a Case Study. In Proceeding of the New Directions in the Teaching of Arabic as a Second Language Conference at King Saud University, pp 259-276, King Saud University Publication, Riyadh.

[19] Kearsley, G. (2000). Online education: learning and teaching in cyberspace. Stamford, CT: Thomson Learning.

[20] Krashen, S. (1983). The natural approach: Language acquisition in the classroom. Englewood Cliffs, NJ: Alemany press.

[21] Lan, Y.-J., Chen, N.-S., Li, P., \& Grant, S. (2015). Embodied cognition and language learning in virtual environments. Educational Technology Research and Development, 1-6. doi: 10.1007/s11423-015-9401$\mathrm{x}$

[22] Oliver, M., \&Trigwell, K. (2005). “Can "blended learning be redeemed?”. E-learning 2 (1), (pp 17-26)

[23] Sajjanhar, A. (2012). Virtual worlds for student engagement. Creative Education, 3(6), 796-801.

[24] Sajjanhar, A. \& Faulkner, J. (2014). Exploring second life as a learning environment for computer programming, Creative Education, 5, (1), 53-62.

[25] Savin-Baden, M. (2010). A practical guide to using second life in higher education. Maidenhead: UK: Open University press.

[26] Sharma, P. (2010). Blended Learning, ELT Journal, Volume 64/4, Oxford University Press:

[27] Sharma, P., \& Barrett, B., (2007). Blended Learning: Using Technology in and Beyond the Language Classroom. Oxford: Macmillan.

[28] Sykes, J., Oskoz, A., \& Thorne, S. L. (2008). Web 2.0, synthetic immersive environments, and mobile resources for language education. Calico Journal, 25(3), 528-546. https://calico.org/memberBrowse.php?action=article\&id=715

[29] Thomas, M. (Ed.). (2008). Handbook of research on Web 2.0 and second language learning. Hershey, PA: IGI Global.

[30] Peregoy, S. \& Boyle, O. (2001). Reading, writing and learning in ESL: A resource book for K -12 teachers.

[31] Wang, S., \&Vásquez, C. (2012). Web 2.0 and second language learning: What does the research tell us? Calico Journal, 29(3), 412-430. http://camillavasquez.com/pdf/WangVasquez_Web2_CALICO.pdf

[32] Warburton, S. (2009). Second Life in higher education. British Journal of Educational Technology, 40(3), 414-426. doi:10.1111/j.1467-8535.2009.00952.x 